\title{
Development of Niobium Based Coatings Prepared by Ion-Plasma Vacuum-Arc Deposition
}

\author{
V.S. Taran, ${ }^{a}$ I.E. Garkusha, ${ }^{a, b}$ O.I. Tymoshenko, ${ }^{a}$ A.V.Taran, ${ }^{a}$ I.O. Misiruk, ${ }^{a,{ }^{*}}$ \\ T.S. Skoblo, ${ }^{c}$ S.P. Romaniuk, ${ }^{c}$ V.V. Starikov, ${ }^{d}$ A.A. Baturin, ${ }^{d} \&$ G.P. Nikolaychuk ${ }^{d}$ \\ aNational Science Center, Kharkiv Institute of Physics and Technology, Institute of Plasma \\ Physics, Kharkiv, Ukraine; ${ }^{b} \mathrm{~V}$. N. Karazin Kharkiv National University, Kharkiv, Ukraine; \\ 'National Technical University of Agriculture, Kharkiv, Ukraine; dNational Technical University, \\ Kharkiv Polytechnic Institute, Kharkiv, Ukraine
}

*Address all correspondence to: Ivan Misiruk, National Science Center, Kharkiv Institute of Physics and Technology (NSC KIPT), Institute of Plasma Physics, Kharkiv, Ukraine; Tel.: +380-57-3356122; Fax: +380-57-3352664, E-mail: ivanmisiruk@gmail.com

\begin{abstract}
Comparative studies of niobium carbide and niobium carbonitride coatings deposited on AISI 430 stainless steel have been presented. The $\mathrm{NbC}$ and $\mathrm{NbCN}$ coatings have been deposited by vacuum-arc evaporation in Bulat-type device by using the pulsed biasing mode with repetition frequency $50 \mathrm{kHz}$, allowing decreasing the micro-arcs formation. An additional magnetic coil for plasma flow focusing was used, allowing one to enhance deposition rate up to $35 \mu \mathrm{m} / \mathrm{h}$. The phase composition of the obtained coatings was analyzed via X-ray diffraction. The surface morphology was monitored by scanning electron microscopy; whereas, chemical composition was examined by using energy dispersive X-ray analysis. X-ray fluorescent analysis was used to evaluate the thickness of the coatings. The reflectance $R(\lambda)$ of the obtained coatings in the wavelength $300-625 \mathrm{~nm}$ at normal incidence was measured. The XRD data from $\mathrm{NbC}$ coating revealed the existence of the niobium carbide phase with a NaCl-type lattice with fine-crystalline grains ranging from 14 to $16 \mathrm{~nm}$. For the $\mathrm{NbCN}$ coating, the two-phase state with c-NbC and hexagonal $\mathrm{NbN}_{0.95}$ phases was monitored. The average grain size for $\mathrm{c}-\mathrm{NbC}$ phase comprised 16-17 nm; whereas, for $\mathrm{NbN}_{0.95}$ the average grain size was only 1-2 nm, confirming formation of a nanocrystalline structure. Surface nanomechanical behavior under nanoindentation of $\mathrm{NbC}$ and $\mathrm{NbCN}$ was studied. It was revealed that nanohardness for a $\mathrm{NbC}$ coating was varied from 30 to $43 \mathrm{GPa}$; whereas, for $\mathrm{NbCN}$ the data spread comprised 30-48 GPa. It was established that the surface of the grown coatings was very smooth with an extremely low amount of macroparticles.
\end{abstract}

KEY WORDS: coating, structure, nanohardness, niobium carbonitride, niobium carbide, ionplasma vacuum-arc deposition, pulsed biasing mode

\section{INTRODUCTION}

Transition metals, such as tantalum and niobium, are excellent candidates as biocompatible coatings for various medical applications including dental implants. ${ }^{1,2} \mathrm{Nb}$ has a lower melting point, lower density, and greater availability and therefore has lower cost in comparison to Ta. Applications of $\mathrm{Nb}$ as a metal or as an alloying addition can be found in cathodic protection systems, heat exchangers, electronic components, superconductors, cutting and grinding tools, the nuclear industry, and more. 
Niobium has largely been used in Ti-6Al-4V titanium alloys to replace strong cytotoxic vanadium and $\mathrm{Al}$ associated with Alzheimer's disease. ${ }^{3,4} \mathrm{Nb}$ has good corrosion resistance, osteogenesis and biocompatibility; in fact, it is one of the elements that does not produce an adverse reaction with surrounding tissues. ${ }^{5,6}$ Matsuno et al. ${ }^{7}$ implanted $\mathrm{Ti}, \mathrm{Hf}, \mathrm{Nb}, \mathrm{Ta}$, and $\mathrm{Re}$ in rats to investigate their osteoconductivity and proved that the amount of new bone formed around the $\mathrm{Nb}$ implant after four weeks is higher than that formed around the other samples, indicating better osseointegration of the $\mathrm{Nb}$ implant. In terms of mechanical properties, $\mathrm{Nb}$ and its alloys have been used for their good mechanical resistance, high melting point and high hardness, and even as reinforcement particles on composite materials with a metal matrix. ${ }^{8}$

The niobium coatings, with the addition of nitrogen and carbon, have a superior performance related to the surface wear reduction and lower corrosion rate compared to uncoated 316L stainless steel substrate and substrate coated with $\mathrm{Nb}$. This behavior could be explained by the presence of $\mathrm{NbC}$ and $\mathrm{NbN}$ phases identified by means of $\mathrm{X}$-ray diffraction (XRD) and the modification it induces in the $\mathrm{Nb}$ cubic structure. ${ }^{9}$ Such a combination of physical properties indicates a complex chemical bonding between the metallic element and carbon. The crystalline structure is typically of the NaCl-type or hexagonal, as is observed for the carbides of the early transition metals. ${ }^{10}$ It was reported by $\mathrm{Xu}^{11}$ that the $\mathrm{NbC}$ films obtained with nonreactive and reactive magnetron sputtering on silicon (100), glass, and AISI 316LVM steel has the highest potential for dental implant surface modification in comparison to $\mathrm{Nb}, \mathrm{NbO}$, and $\mathrm{NbN}$ films. The nanohardness values were rather low and comprised $\mathrm{Nb}=6.6 \mathrm{GPa}, \mathrm{NbC}=12.0 \mathrm{GPa}, \mathrm{NbN}=16.0 \mathrm{GPa}$, and $\mathrm{NbO}=7.8 \mathrm{GPa}$.

Techniques such as chemical vapor deposition and physical vapor deposition allow applying $\mathrm{Nb}, \mathrm{NbC}, \mathrm{NbN}$, and $\mathrm{Nb}_{2} \mathrm{O}_{5}$ of a huge variety of materials with different composition and microstructure. Mostly, $\mathrm{Nb}$ based coatings have been applied by using direct current (DC) or radio frequency (RF) magnetron sputtering. ${ }^{12}$ However, there is lack of data considering vacuum-arc evaporation techniques to produce niobium carbide and niobium carbonitride coatings.

In this paper, the $\mathrm{NbC}$ and $\mathrm{NbCN}$ coatings have been deposited by vacuum-arc evaporation in a Bulat-type device by using pulsed biasing mode. The structure, chemical composition, and mechanical properties have been evaluated in order to modulate the coatings behavior on dental implants material made of stainless steel. The surface modification by thin-film technology can improve interaction between living tissues and implant base material due to various bioinert coatings having high hardness value, resistance to mechanical wear and corrosion, and good adhesion to the substrate.

\section{A. Materials and Methods}

$\mathrm{NbC}$ and $\mathrm{NbCN}$ coatings were synthesized by vacuum-arc deposition on AISI $430 \mathrm{SS}$ substrates of $25 \times 25 \times 3 \mathrm{~mm}$ size in a Bulat-type device, described elsewhere. ${ }^{13}$ Before deposition, the substrates were cleaned in an ultrasonic bath with alcohol for $10 \mathrm{~min}$. Chemically pure niobium (99.99\%) was used as a cathode material. First, the pulsed negative biasing of $10 \times 10^{2} \mathrm{~V}$ with a frequency of $50 \mathrm{kHz}$ was applied to the sample 
holder for substrate cleaning and degreasing. Next, a thin $\mathrm{Nb}$ buffer layer of $20 \mathrm{~nm}$ thickness was deposited before the carbide and carbonitride coatings to improve coatings adhesion. For $\mathrm{NbCN}$ coatings, the $\mathrm{N}_{2}$ and $\mathrm{C}_{4} \mathrm{H}_{10}$ gas mixture was used. The nitrogen pressure in the deposition process was about $4.5 \times 10^{-3}$ Torr, and the $\mathrm{CH}$ pressure was $6.5 \times 10^{-3}$ Torr. The deposition rate was $\sim 35 \mu \mathrm{m} / \mathrm{h}$ and deposition time was $\sim 13 \mathrm{~min}$.

The surface topography of $\mathrm{NbC}$ and $\mathrm{NbCN}$ were studied using a JEOL JSM-6390LV scanning electron microscope (SEM) with an accelerating voltage of $20 \mathrm{KV}$, and the chemical composition was examined using energy-dispersive X-ray analysis (EDX). An energy-dispersive spectrometer SPRUT-K (AO Ukrrentgen, Ukraine) was used for X-ray fluorescent analysis and equipped with a Sc (Li) X-100 detector (Amptek, Bedford, MA) in the arrangement with $\mathrm{Si}$ and $\mathrm{KCl}$ secondary target. Film thickness was determined by X-ray fluorescent analysis examinations and comprised $6 \mu \mathrm{m}$ for $\mathrm{NbCN}$ and $9.7 \mu \mathrm{m}$ for $\mathrm{NbC}$ coatings. X-ray diffraction (XRD) analysis were performed using a DRON-3M device, under $\mathrm{Cu}-\mathrm{K} \alpha$ radiation, monochromated by (002) HOPG in a diffracted beam. The XRD line scans were performed in $\theta-2 \theta$ scanning mode, where the incident angle $\theta$ and diffracted angle $2 \theta$ were scanned simultaneously.

The nanohardness was measured by a Nanoindenter G200 (Agilent Technologies Inc, Santa Clara, CA, USA). The loading and unloading rates of the nanoindentation were $10 \mathrm{mN}$. Samples were tested to a depth of $500 \mathrm{~nm}$. Eight prints were made for each sample, and the distance between prints was $15 \mu \mathrm{m}$. Reflectance $(R)$ at normal incidence in the wavelength range of 300-625 nm was measured by using a microscope spectrophotometer MCFU-K (LOMO).

\section{RESULTS AND DISCUSSION}

Figures 1(a) and 1(b) show the XRD spectra of both $\mathrm{NbC}$ and $\mathrm{NbCN}$ coatings. The NbC spectrum in Fig. 1(a) shows peaks with crystallographic planes (111), (002), (022), and (113) corresponding to the phase $\mathrm{NbC}$ of cubic modification $(a=4.46910 \AA)$ in
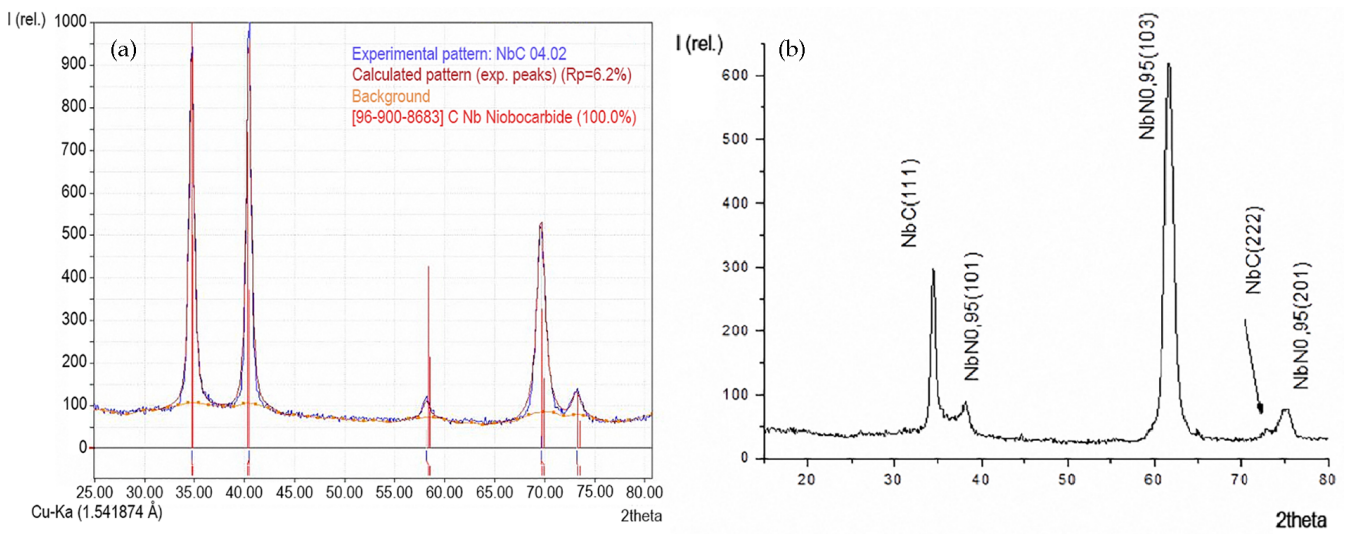

FIG. 1: XRD diffraction patterns taken from (a) NbC and (b) NbCN coatings 
accordance with the ICDD 96-900-8683 reference pattern. No additional phases were detected. The carbonitride film shows a two-phase state with diffraction peaks from cubic phase of $\mathrm{NbC}$ and hexagonal phase of $\mathrm{NbN}_{0.95}$ in accordance with ASTM card 23-1363.

Niobium nitrides and carbides generate compounds with ionic and covalent bonds. The ionic character for $\mathrm{NbN}$ is of $40.04 \%$, and $\mathrm{NbC}$ presents an ionic character of $18.3 \%{ }^{8}$ Introducing nitrogen or carbon atoms into the niobium crystalline structure induces structural changes from a body-centered cubic (BCC) with a cell parameter of $3.3280 \AA$ to a $\mathrm{NaCl}$-like structure with a cell parameter of $4.4790 \AA$, where $\mathrm{Nb}^{+}$cations occupy interstitial sites between atomic sites of a face-centered cubic (FCC) carbon cell. The crystallite size of the coatings was calculated from the full-width-at-half-maximum (FWHM) intensity $(\beta)$ of the X-ray diffraction angle $(\theta)$ of the diffraction peak and the wavelength $(\lambda)$ of the copper X-ray radiation using the Debye-Scherrer relation, ${ }^{14}$ assuming that no strains were developed in the coatings

$$
D=\frac{\mathrm{K} \lambda}{\beta} \cos \theta
$$

where $\mathrm{K}$ is an $\mathrm{X}$-ray radiation-dependent constant $(\mathrm{K}=0.9$ for $\mathrm{Cu}-\mathrm{K} \alpha)$ and $\theta$ is the diffraction angle. The crystallite size of the niobium carbide film deduced was 14-16 nm. For the two-phase $\mathrm{NbCN}$ coating, the grain size of $\mathrm{NbC}$ phase was 16-17 $\mathrm{nm}$ and for $\mathrm{NbN}_{0.95}$ comprised 1-2 nm.

The surface morphology and chemical composition of $\mathrm{NbC}$ and $\mathrm{NbCN}$ coatings were examined by using a scanning electron microscope (JEOL JSM-6390LV), equipped with EDX (Figs. 2(a)-2(d)). The surfaces of both coatings are similar with a faceted structure and very smooth, having a small number of macrodefects identified as drops from the cathode material. The size of macroparticles $<2 \mu \mathrm{m}$.

In accordance with energy-dispersive X-ray analysis (Figs. 3(a) and 3(b)), the integral chemical composition of the $\mathrm{NbC}$ coating was $\mathrm{Nb}-66.86$ at. $\%, \mathrm{O}-4.61$ at.\%, and $\mathrm{C}-28.53$ at. $\%$. The chemical composition of $\mathrm{NbCN}$ coating was $\mathrm{Nb}-25.68$ at.\%, $\mathrm{C}-36.35$ at.\%, $\mathrm{N}-34.58$ at.\%, and $\mathrm{O}-3.38$ at.\%. The presence of a small quantity of oxygen is due to residual gas incorporated in the chamber walls and contamination during sample handling in an open atmosphere before the composition analysis.

The microhardness of the coating strongly depends on structural parameters such as crystallographic orientation, microstress, and crystallite size. One of the main characteristics of the material is the ratio of its hardness to the elastic modulus $H / E$, called plasticity index. The ratio $H^{3} / E^{* 2}$, where $E^{*}=E /\left(1-\mu^{2}\right)$ - the effective elastic modulus; $\mu$ - Poisson's ratio, is also a qualitative comparative characteristic of the plastic deformation resistance. To increase the plastic deformation resistance, it is required to strive for the lowest possible elastic modulus at high hardness, which, in particular, takes place at grain sizes of $<10 \mathrm{~nm}$.

The effective elastic modulus $E^{*}$, the shear modulus $G$, yield stress point $\sigma_{\mathrm{T}}$, and coefficient of resistance to plastic deformation $H^{3} / E^{* 2}$ were determined using model equations. The shear modulus and yield stress are defined as follows: $G=E / 2 \times(1+\mu)$; $\sigma_{\mathrm{T}}=H \mu / 3$. 

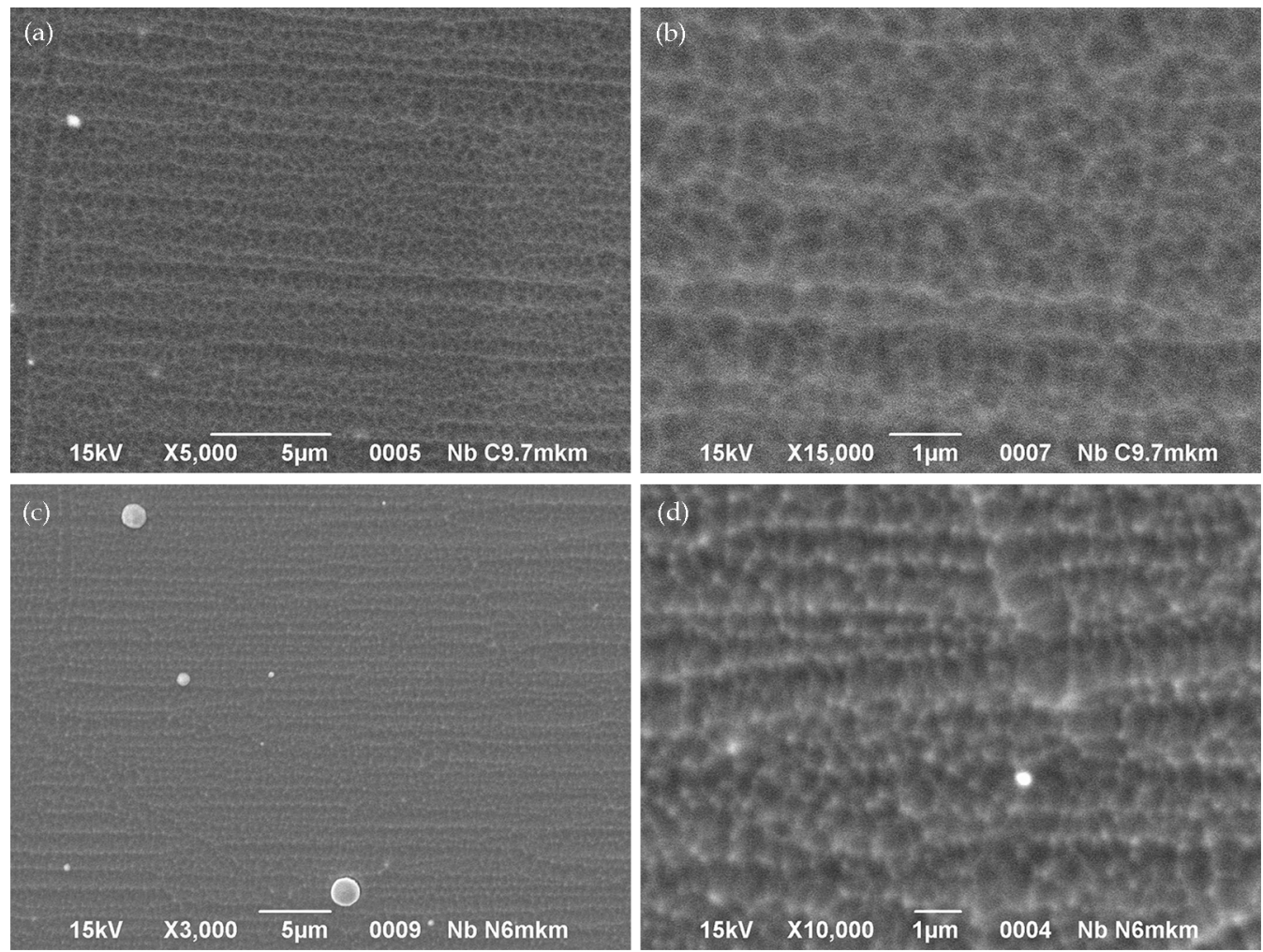

FIG. 2: $\mathrm{SEM}$ images taken from $(\mathrm{a}, \mathrm{b}) \mathrm{NbC}$ and $(\mathrm{c}, \mathrm{d}) \mathrm{NbCN}$ coatings
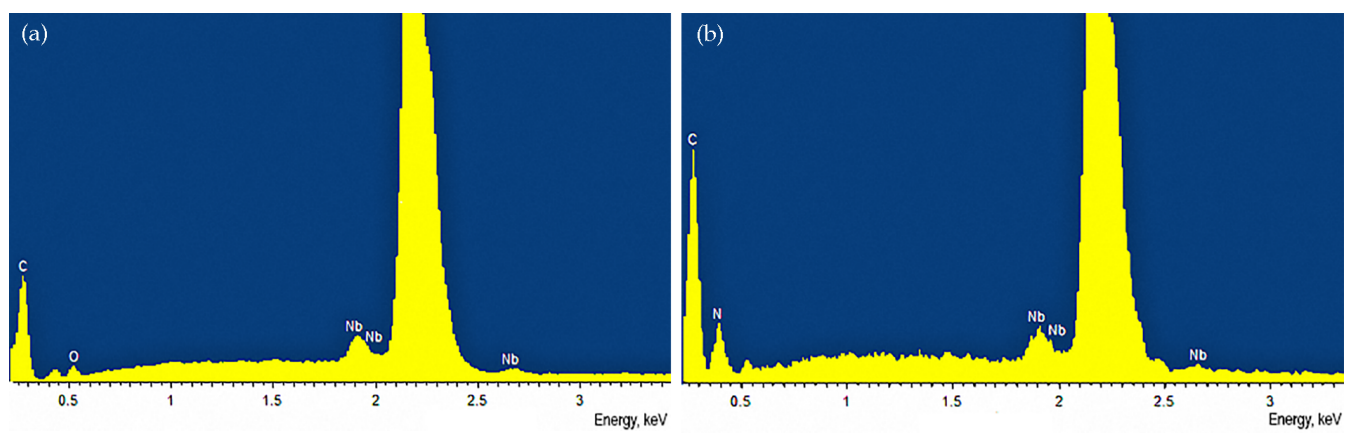

FIG. 3: EDX spectra of (a) $\mathrm{NbC}$ and (b) $\mathrm{NbCN}$ coatings

The nanoidentation diagrams for $\mathrm{NbC}$ and $\mathrm{NbCN}$ coatings are presented in Fig. 4. The results of $H$ and $E$ values, $G, \sigma_{\mathrm{T}}$, and $H^{3} / E^{* 2}$ are summarized in Table 1 . These hardness values of the niobium-based coatings are higher than the hardness of stainless steel substrates, which was also measured in mirror-polished samples ( $\sim \mathrm{GPa})$, suggesting 

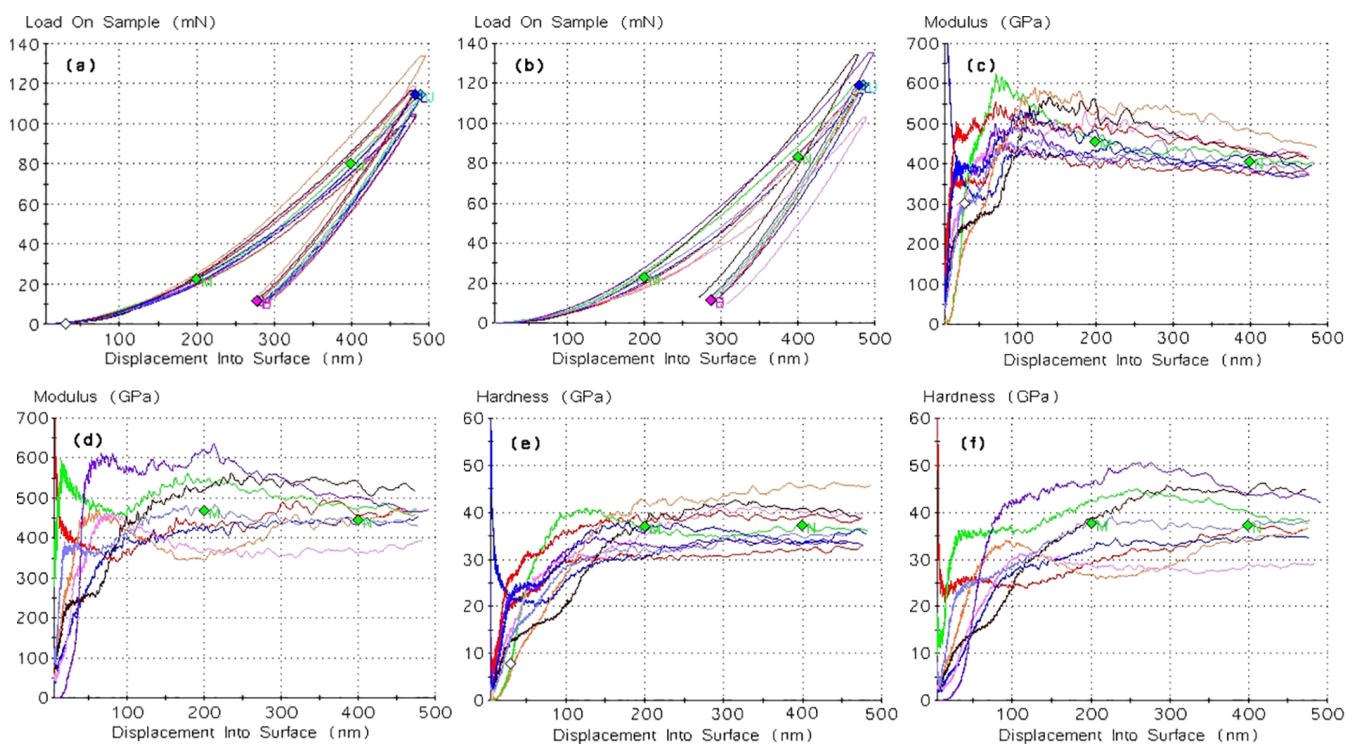

FIG. 4: Nanoidentation diagrams for the $\mathrm{NbC}$ and $\mathrm{NbCN}$ coating: (a-b) load-unload diagrams, (c-d) elastic modulus and (e-f) nanohardness, respectively

TABLE 1: Mechanical characteristics of niobium-based coatings

\begin{tabular}{|l|c|c|c|c|c|c|c|c|c|}
\hline \multicolumn{1}{|c|}{ Sample } & E GPa & H GPa & $\mathbf{H} / \mathbf{E}$ & $\mathbf{H}^{3} / \mathbf{E}^{2}$ & $\mathbf{E}^{*}$ & $\mathbf{H}^{3} / \mathbf{E}^{* 2}$ & $\mathbf{G}, \mathbf{G P a}$ & $\boldsymbol{\sigma}_{\mathbf{T}}, \mathbf{G P a}$ \\
\hline \multicolumn{8}{|c|}{ Average data from eight prints } \\
\hline $\mathrm{NbCN}$ & 465.588 & 36.812 & 0.079 & 0.233 & 496.627 & 0.205 & 290.992 & 12.271 \\
\hline $\mathrm{NbC}$ & 428.073 & 35.901 & 0.084 & 0.253 & 456.611 & 0.222 & 267.55 & 11.97 \\
\hline AISI 430 SS & 201.151 & 4.092 & 0.020 & 0.001 & 230.231 & 0.05 & 121 & 9.66 \\
\hline
\end{tabular}

that there is essential improvement of the surface mechanical properties by the deposition of any of the coatings. Such high hardness is achieved due to formation of a nanocomposite structure consisting of two or more phases coexisting in a very small volume, crystals having dimensions of $2-20 \mathrm{~nm}$. In the case of nanocrystalline materials, the number of atoms in the crystalline grain is comparable to or even less than the number of atoms within the grain. In such conditions, the formation of dislocations is inhibited by the grain boundary, and mechanical deformation occurs by the mechanism of sliding beyond the grain rather than by the dislocation of motion, which is a deformation mechanism in ordinary materials. This leads to a significant increase in the hardness of nanocrystalline materials and to the development of superhard materials.

Reflectance of the niobium-based coatings was measured in the range from 300 to $625 \mathrm{~nm}$ and compared to mirror-polished AISI 430 stainless steel substrate. The data obtained are presented in Table 2. The results showed in a decrease in reflectance as compared to the case of initial stainless steel surface. Figure 5 shows a graph representation 


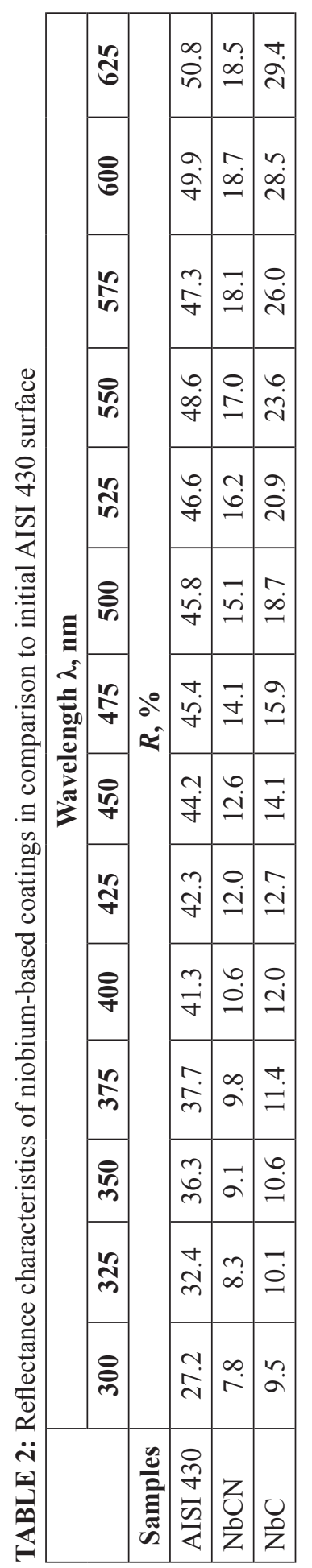




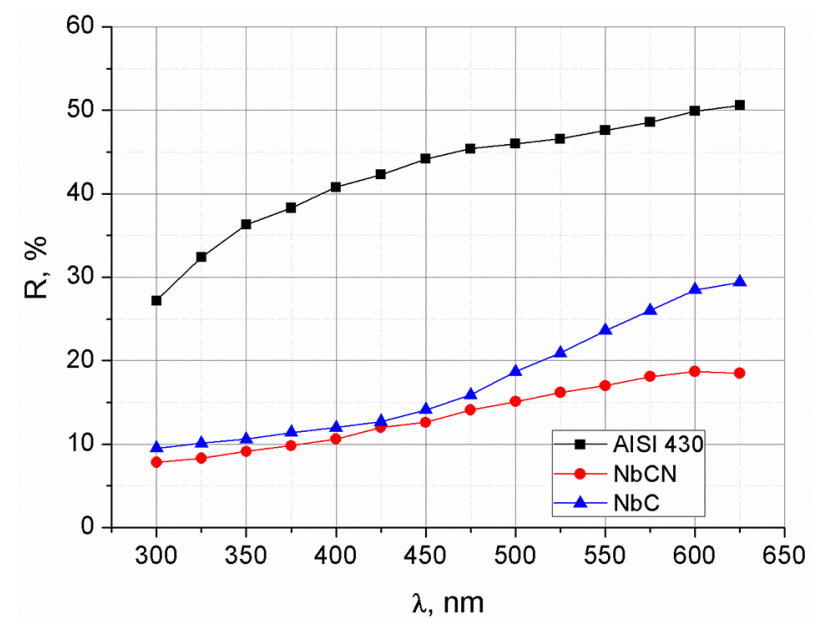

FIG. 5: Wavelength dependences of the initial reflectance (AISI 430 SS) and the reflectance of $\mathrm{NbCN}$ and $\mathrm{NbC}$ coatings

of wavelength dependences of the initial reflectance (AISI 430 SS) and the reflectance of $\mathrm{NbCN}$ and $\mathrm{NbC}$ coatings.

\section{CONCLUSIONS}

Niobium-based coatings were deposited by using an ion-plasma vacuum-arc deposition technique with pulsed biasing mode on stainless steel (SS) substrates to evaluate them as possible surfaces that might extend the lifetime of SS dental implants. The proposed technology allowed minimizing the amount of micro-arc formations. Additional magnetic coil for plasma flow focusing was used, allowing one to enhance deposition rate up to $35 \mu \mathrm{m} / \mathrm{h}$. The XRD data from $\mathrm{NbC}$ coating revealed the existence of a niobium carbide phase with $\mathrm{NaCl}$-type lattice with fine-crystalline grains ranging from 14 to $16 \mathrm{~nm}$. For the $\mathrm{NbCN}$ coating, the two-phase state with c-NbC and hexagonal $\mathrm{NbN}_{0.95}$ phases was monitored. The average grain size for c-NbC phase comprised 16-17 nm; whereas, for $\mathrm{NbN}_{0.95}$ the average grain size was only $1-2 \mathrm{~nm}$, confirming formation of a nano-crystalline structure. It was revealed that nanohardness for $\mathrm{NbC}$ coating varied from $30-43 \mathrm{GPa}$; whereas, for $\mathrm{NbCN}$ the data spread comprised 30-48 GPa. Reflectance of the niobium-based coatings was measured in the range of 300-625 nm and compared to mirror-polished AISI 430 stainless steel substrate. The proposed technology would be prospective for applying niobium coatings on dental implants made of stainless steel or Ti6A14V alloy.

\section{REFERENCES}

1. Ramirez G, Rodil SE, Arzate H, Muhl S, Olaya JJ. Niobium based coatings for dental implants. Appl Surf Sc. 2011;257(7):2555-9. 
2. Shi J, Zhang X, Qiao S, Ni J, Mo J, Gu Y, La H. Enhanced osteointegration of tantalum-modified titanium implants with micro/nano-topography. RSC Adv. 2017;7:46472-9.

3. Okazaki Y, Ito Y, Ito A, Tateishi T. Effect of alloying elements on mechanical properties of titanium alloys for medical implants. Mater Trans JIM. 1993;34:1217-22.

4. Okazaki Y, Rao S, Tateishi T, Ito Y. Cytocompatibility of various metals and development of new titanium alloys for medical implants. Mater Sci Eng A. 1998;243(1-2):250-6.

5. Maya AEA, Grana DR, Hazarabedian A, Kokubu GA, Luppo MI, Vigna G. Zr-Ti-Nb porous alloys for biomedical application. Mater Sci Eng C. 2012;32(2):321-9.

6. Braic M, Braic V, Balaceanu M, Vladescu A, Zoita CN, Titorencu I, Jing V. Preparation and characterization of biocompatible Nb-C coatings. Thin Solid Films. 2011;519(12):4064-8.

7. Matsuno H, Yokoyama A, Watari F, Uo M, Kawasaki T. Biocompatibility and osteogenesis of refractory metal implants, titanium, hafnium, niobium, tantalum and rhenium. Biomaterials. 2001;22:1253-62.

8. Cuppari MGV, Santos SF. Physical properties of the NbC carbide. Metals. 2016;6(10):250.

9. Han MK, Kim JY, Hwang MJ, Song HJ, Park YJ. Effect of Nb on the microstructure, mechanical properties, corrosion behavior, and cytotoxicity of Ti-Nb alloys. Materials. 2015;8(9):5986-6003.

10. Guzmana P, Caballeroa JL, Orozco-Hernándezb G, Aperadora W, Caicedo JC. Tribocorrosion behavior of niobium-based thin films for biomedical applications. Tribol Indust. 2018;40(4):624-32.

11. Xu Z, Yate L, Qiu Y, Aperador W, Coy E, Jiang B, Moya S, Wang G, Pan H. Potential of niobiumbased thin films as a protective and osteogenic coating for dental implants: The role of the nonmetal elements. Mat Sci Eng C. 2019;96:166-75.

12. Venkataraj S, Drese R, Kappertz O, Jayavel R, Wuttig M. Characterization of niobium oxide films prepared by reactive DC magnetron sputtering. Phys Status Solidi A. 2001;188:1047-58.

13. Taran AV, Garkusha IE, Taran VS, Muratov RM. Anti-corrosion ceramic coatings on the surface of Nd-Fe-B repelling magnets. Probl Atom Sci Technol. 2019;25(1):116-9.

14. Cullity DB. Elements of x-ray diffraction. 2nd ed. Boston: Addison Wesley; 1978.

Volume 10, Issue 1, 2020 
